International Journal of Current Advanced Research

ISSN: O: 2319-6475, ISSN: P: 2319 - 6505, Impact Factor: SJIF: 5.995

Available Online at www.journalijcar.org

Volume 6; Issue 5; May 2017; Page No. 3822-3825

DOI: http://dx.doi.org/10.24327/ijcar.2017.3825.0375

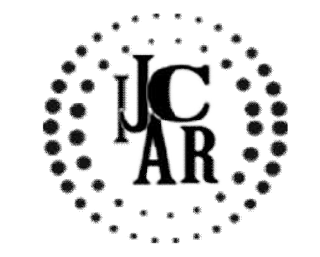

Research Article

\title{
CLINICAL APPLICATION OF SPECTRA A MODE IN HYSTEROSCOPY GUIDED ENDOMETRIAL BIOPSY
}

\section{Nirmal Bhargava., Rahul Manchanda., Sudhir Kulkarni., Stuti Tyagi* and Jahnavi Meena}

Fellow in Gynecology Endoscopy, Gynecology Endoscopy Unit, PSRI Hospital, New Delhi

\section{A R T I C L E I N F O}

\section{Article History:}

Received $9^{\text {th }}$ February, 2017

Received in revised form $12^{\text {th }}$ March, 2017

Accepted $17^{\text {th }}$ April, 2017

Published online $28^{\text {th }}$ May, 2017

\section{Key words:}

SPECTRA A filter, hysteroscopy,

endometrial biopsy

\begin{abstract}
A B S T R A C T
In the management of adaptation and mitigation processes for climate change, it is important to find appropriate governance tools. In this work we propose a GIS-based system, based on an intelligent probabilistic model. The model operates on climate, environmental and socio-economic data. The proposed system performs sophisticated analysis through spatial queries and provides useful answers to the territorial governance. It could be used to define territorial policies in order to mitigate or adapt the social and economic choices to the climate change.
\end{abstract}

Copyright $₫ 2017$ Stuti Tyagi et al. This is an open access article distributed under the Creative Commons Attribution License, which permits unrestricted use, distribution, and reproduction in any medium, provided the original work is properly cited.

\section{INTRODUCTION}

In hysteroscopy, the uterine cavity is directly observed using an endoscope. This method is used as a gynecological examination of the uterine cavity in patients with suspected endometrial lesions. Hysteroscopy has been suggested to be a superior examination for investigation of the uterine cavity $(1,2)$, and high diagnostic accuracies for abnormalities in the uterine cavity (3) and endometrial carcinoma have been achieved in studies comparing hysteroscopy and histology $(4,5)$.

New techniques of diagnostic endoscopy are being developed with rapid speed. To achieve early identification of precancerous lesions and then initiate targeted and definitive therapy immediately, the modern endoscopist must keep abreast with new technologies. In this endeavor the endoscopist is supported by common filter technologies.

SPIES are an acronym for Storz Professional Image Enhancement System. This system offers several image enhancement modalities that can be used in combination with SPIES adapted camera heads and video endoscopes. Five SPIES modalities, besides a conventional white light image, are available: Chroma, Clara, Clara and Chroma combined, Spectra A and Spectra B. The Chroma modality should enhance the sharpness of the image. The Clara modality is designed to create a clearer image of darker regions within the image.

*Corresponding author: Stuti Tyagi

Fellow in Gynecology Endoscopy, Gynecology Endoscopy Unit, PSRI Hospital, New Delhi
Together they should provide a clearer and sharper image of the original WL image. The Spectra A and Spectra B modality change the effective spectral response in the imaging system, which should lead to a better color contrast (6).

The Spectra A and B might improve the evaluation of images by changing the color response and thus the contrast that would help in differentiation of normal mucosa and tumor.

In our study, we compared the hysteroscopic images under white light and Spectra A mode in patients with complaints of AUB and send the endometrial biopsy taken under both white light and spectra A mode for histopathological examination. This study is done with the aim to study the role of spectra A filter in improving visualization, which will result in a more appropriate hysteroscopic endometrial biopsy, so that timely and accurate further management can be done.

\section{MATERIAL AND METHODS}

This is a 4 months hospital based prospective study of patients attending gynecology endoscopy clinic, at department of gynecology endoscopy, Pushpawati Singhania research institute (PSRI hospital), Sheikh Sarai, Delhi. This study is conducted from September 2016 to December 2016.

All patients with complaints of abnormal uterine bleeding and postmenopausal bleeding were included in the study. Demographic data such as age, marital status and parity were included in this study. All patients were posted for diagnostic and operative hysteroscopy with endometrial biopsy after preoperative workup. 
Hysteroscopy was done with $2.9 \mathrm{~mm}$ diameter, $30^{\circ}$ bettochhi hysteroscope with an operative sheath attached to a Karl Storz image 1 connects (TC200) SPIES camera and a xenon light source. All procedures were done under general anesthesia by same surgeon. Distension of uterine cavity was achieved with normal saline by endomat. Hamou endomat was used as fluid delivery system with inflow pressure of $150 \mathrm{~mm}$ and outflow pressure of 0.5 bars. No prior cervical dilatation was done. Hysteroscope was introduced through the external os after white balancing and advanced directly under vision through the endocervical canal into the cavity of the uterus. Entire uterine cavity with all four walls and bilateral Ostia were visualized. Video images were analyzed under white light first, and then mode was switched to Spectra A by pressing a button on the camera. Then both the images were compared. Endometrial biopsies were taken from suspicious areas under both white light and Spectra A filter using 5 Fr scissors. Biopsies were sent for HPE and the reports were analyzed and compared. If any pathology like polyp, myoma was diagnosed, operative procedure was done at the same sitting. Video recording of each procedure was done for future reference.

\section{RESULT}

Out of 23 patients attending gynecology endoscopy clinic with complaints of abnormal uterine bleeding and postmenopausal bleeding, only 19 patients gave consent for hysteroscopic guided biopsy from September 2016 till December 2016. Patient's age ranged from 32 yrs to $57 \mathrm{yrs}$ with mean and median of 36.44 yrs and 37 yrs. Out of 19 patients $16(84.21 \%)$ were married and $3(15.78 \%)$ were unmarried.

Five (26.31\%) patients had complaints of postmenopausal bleeding, $12(63.15 \%)$ had heavy menstrual bleeding and 2 $(10.52 \%)$ patients had inter menstrual bleeding.

All patients underwent hysteroscopy under white light and Spectra A mode after initial work up. The SPIES Spectra A changes the effective spectral response in the imaging system. This mode allows to highlight the contrast of capillaries and vessels in the superficial layers, thus there is better visualization of superficial layers in comparison to white light only (Fig 1).

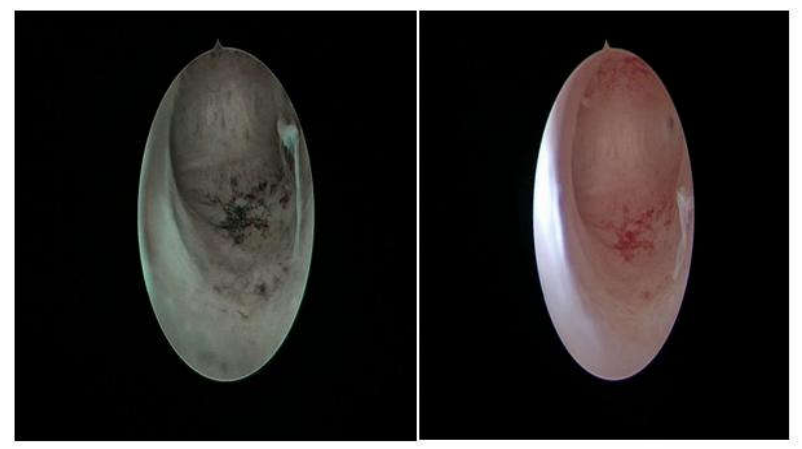

Fig 1 Comparative Between White Light And Spectra A Filter

In easy to evaluate cases, there was no clinically significant difference found in the delineated area between images in white light and Spectra A. In more difficult to evaluate cases, image quality in SPIES Spectra A was graded significantly higher than in white light and thus endometrial biopsies were taken from better visualized, vascularised and suspicious areas. Though no major difference was found in the histopathological reports between the two modes i.e. white light and SPECTRA A filter. (Table 1 and 2)

Table 1 Showing comparison between white light and Spectra A mode on hysteroscopy

\begin{tabular}{ccc}
\hline Findings in patients & $\begin{array}{c}\text { No. of patients } \\
\text { under white light }\end{array}$ & $\begin{array}{c}\text { No. of patients } \\
\text { under spectra a } \\
\text { mode }\end{array}$ \\
\cline { 2 - 3 } Endometrial polyp & 3 & 3 \\
Fibroid polyp & 2 & 2 \\
Hyperplastic endometrium & 3 & 3 \\
Atrophic endometrium & 3 & 3 \\
Endometrium with increased & 2 & 4 \\
vascularity & 6 & 4 \\
Normal looking endometrium & & \\
\hline
\end{tabular}

Table 2 Showing results of our study i.e. comparison between white light and Spectra A mode on histopathology.

\begin{tabular}{|c|c|c|}
\hline $\begin{array}{c}\text { Histopathological Findings in } \\
\text { Patients }\end{array}$ & $\begin{array}{c}\text { No. of patients } \\
\text { under white } \\
\text { light }\end{array}$ & $\begin{array}{c}\text { No. of patients } \\
\text { under spectra } \\
\text { a mode } \\
\end{array}$ \\
\hline Endometrial adenomatous polyp & 2 & 2 \\
\hline $\begin{array}{l}\text { Endometrial adenomatous polyp } \\
\text { with mild nuclear atypia }\end{array}$ & 1 & 1 \\
\hline $\begin{array}{c}\text { Endometrial hyperplasia without } \\
\text { atypia }\end{array}$ & 1 & 1 \\
\hline $\begin{array}{c}\text { Endometrial hyperplasia with } \\
\text { atypia }\end{array}$ & 2 & 2 \\
\hline Fibroid polyp & 2 & 2 \\
\hline Atrophic endometrium & 3 & 2 \\
\hline $\begin{array}{l}\text { Atrophic endometrium with } \\
\text { inflammatory changes }\end{array}$ & 0 & 1 \\
\hline Proliferative endometrium & 1 & 1 \\
\hline Normal secretory endometrium & 4 & 3 \\
\hline $\begin{array}{l}\text { Secretory endometrium with } \\
\text { mild inflammation }\end{array}$ & 2 & 3 \\
\hline $\begin{array}{l}\text { Decidual changes( hormonal } \\
\text { influence) }\end{array}$ & 1 & 1 \\
\hline
\end{tabular}

\section{DISCUSSION}

Computer and chip technologies have undergone major technological changes which have greatly improved endoscopic diagnostic investigation.

Chromoendoscopy or filter-aided endoscopy (virtual chromoendoscopy) with high definition endoscopes is able to enhance the detection and characterization of lesions. Owing to the previously described modern processor technology of high-resolution endoscopy systems and the possibility to add color by pressing a button and activating a color filter, virtual coloring is currently receiving special attention in endoscopy. The procedure of so-called virtual chromoendoscopy modulates, by the press of a button and with no loss of time, the spectrum of visible light so that the mucous membranes can be visualized (7) The effect of such color accents is that individual components of the mucosa, such as the surface pattern or vascular structures of the mucous membranes can be depicted more clearly (8). The different color spectrums are produced either by modulating the incoming light with filters (NBI technique), or by software-based processing (socalled post-processing) of the reflected light (SPIES) $(9,10)$.

Narrow band imaging (NBI) is an endoscopic imaging technique in which images of micro-blood vessels in the mucosal superficial layer and mucosal surface are enhanced by changing the spectrum of observation light to narrow bands. 
In NBI, the light spectrum is shifted to wavelengths of $415 \pm 30$ and $540 \pm 30 \mathrm{~nm}$, and wavelength-induced changes in visibility are utilized (11).

The SPIES Spectra A mode is based mainly on the green $(\sim 500-570 \mathrm{~nm})$ and blue $(\sim 400-480 \mathrm{~nm})$ light spectral signals that are separated in the RGB response of the camera system. In these bands the hemoglobin absorption is significantly higher compared to the red spectral band above $570 \mathrm{~nm}$. A dedicated color transformation pronounces the contrast within these two spectral bands by changing the perceived output color with respect to the original colors created by this spectral input. Due to the limited penetration depth in the blue to green spectral part, this mode allows to highlight the contrast of capillaries and vessels in the superficial mucosa and sub mucosa (Fig 2, 3).

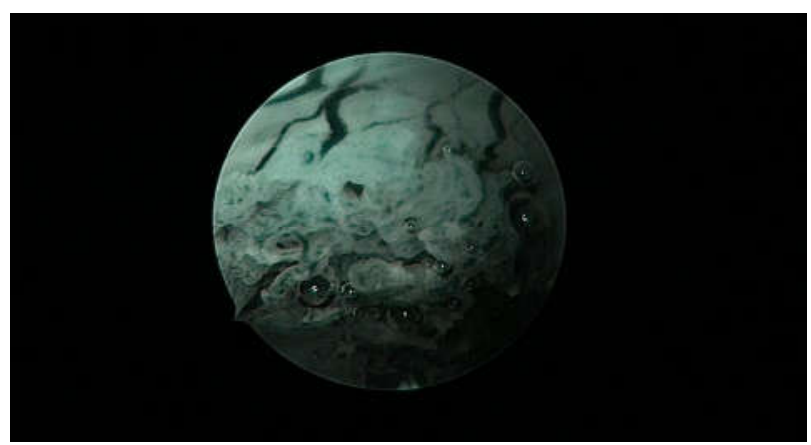

Fig 2 Spectra A Filter Showing Vascularity

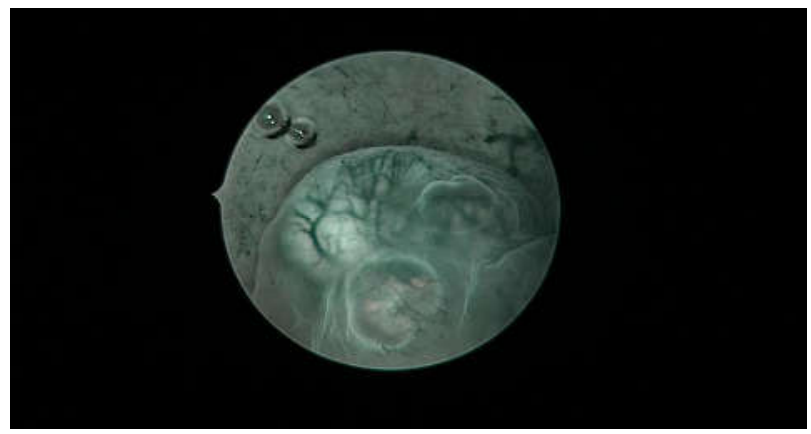

Fig 3 Spectra A Filter Applied For Better Visualisation

In regions other than blood vessels, light enters tissue, scatters and reflects, resulting in a brighter appearance. In the gynecological field, angiogenesis is also considered as a diagnostic marker of a malignant endometrial lesion $(1,2)$. Therefore, identification of increased angiogenesis or abnormal vessels may play a role in diagnosis of malignant lesions, including those in endometrial carcinoma and its precursors (fig 4).

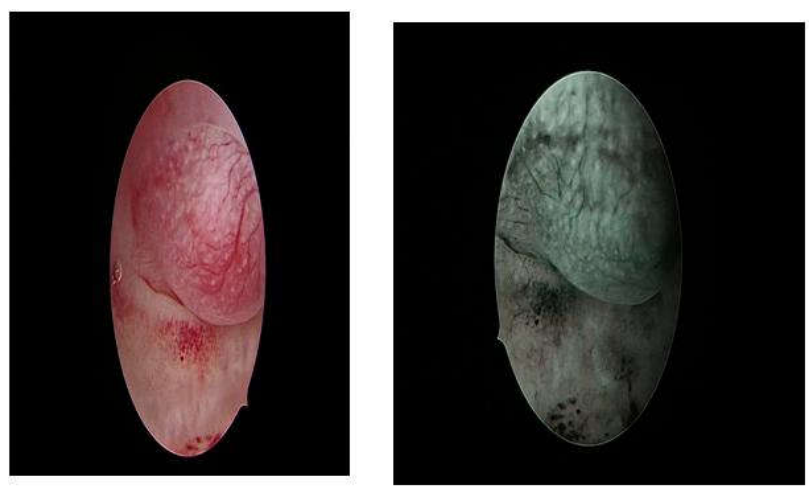

Fig 4 comparative visual of white light and SEPCTRA A
Few studies have been conducted using different color spectrums and comparison was made between white light and narrow band imaging. Kisu et al (11) reported sensitivities for identification of endometrial hyperplasia or endometrial carcinoma as $82.6 \%$ using white light and $97.2 \%$ using white light and narrow band imaging. Cicinelli et al (12) and Surico et al (13) also found that sensitivity for diagnosis of endometrial carcinoma and hyperplasia was significantly higher using narrow band imaging than white light.

But no studies have been conducted yet using SPIES SPECTRA A mode and comparing histopathologically with white light. Our study compared between SPIES spectra A mode and white light both hysteroscopically as well as histopathologically.

To objectify the spectral SPIES modalities, a phantom model was used by Kamphuis GM et al (6) and absorbance was measured and it concluded that the new modalities are indeed different though not necessarily are an improvement for the diagnosis of disease.

The better the quality and clarity of images, the better the patient can be cared for. Thus, the main purpose of endoscopy can be achieved, which is early and timely detection of malignant changes. Our study concludes that a clearer and sharper image and more contrast lead to a higher chance to distinguish differences in Endometrium and thus have a higher detection rate of abnormalities using SPECTRA filter A, though large studies are required to further confirm its role statistically.

\section{Acknowledgement}

I would like to express thanks to my teacher Dr Rahul Manchanda who guided me a lot. Also my thanks to Dr Sudhir kulkarni who helped in my work and to Dr Jahnavi and Dr Stuti who gave me constant support. This is an original research and has not been published before nor yet presented as paper or poster. There is no conflict of interest among authors.

\section{References}

1. Balasch J: Investigation of the infertile couples: investigation of the infertile couple in the era of assisted reproductive technology: a time for reappraisal. Hum Reprod 15: 2000, 2251-2257.

2. Brand A: Diagnosis of endometrial cancer in women with abnormal uterine bleeding. J SOGC 86: 2000, 1-3.

3. Chanbers JT and Chanbers SK: Endometrial sampling: When? Where? Why? With what? Clin Obstet Gynecol 35:1992, 28-39.

4. Creasman WT: Endometrial cancer: incidence, prognostic factors, diagnosis, and treatment. Semin Oncol 24:1997, S1-140-S1-50.

5. Garuti G, Sambruni I, Colonnelli $M$ and Luerti M: Accuracy of hysteroscopy in predicting histopathology of endometrium in 1500 women. $J$ Am Assoc Gynecol Laparosc 8: 2001, 207-213.

6. Kamphuis GM*1, de Bruin DM1,2, Fallert J3, Gultekin MH4, de Reijke TM1, Laguna Pes MP1 and de la Rosette .Storz Professional Image Enhancement System: A New Technique to Improve Endoscopic Bladder Imaging. J Cancer Sci Ther. 8(3):2016, 071 077. 
7. Murthy S, Goetz M, Hoffman A, Kiesslich R. Novel colonoscopic imaging. Clin Gastroenterol Hepatol 10: 2012, 984-87.

8. Sauk J, Hoffman A, Anandasabapathy S, Kiesslich R. High-definition and filter-aided colonoscopy. Gastroenterol Clin North Am. 2010; 39:859-81.

9. Gita Guin, Surpreet Kaur Sandhu, Arvind Lele, and Shashi Khare. Hysteroscopy in Evaluation of Abnormal Uterine Bleeding. J Obstet Gynaecol India. 2011 Oct; 61(5): 546-49.

10. Bettochi S, Nappi L, Ceci O, et al. Office hysteroscopy. Obstetrics and gynecology clinics of North America: advances in laparoscopy and hysteroscopy techniques, Philadelphia: W.B. Saunders Company; 2004. p. 641-54.
11. Iori kisu, kouji banno, yusuke kobayashi, asuka ono, kenta masuda, arisa ueki et al. Narrow band imaging hysteroscopy: A comparative study using randomized video images. International Journal of oncology 39: 2011, 1057-62,.

12. Cicinelli E, Tinelli R, Colafiqlio G, et al: Reliability of narrowband imaging (NBI) hysteroscopy: a comparative study. Fertil Steril 94: 2010, 2303-07.

13. Surico D, Vigone A, Bonvini D, Tinelli R, Leo L and Surico N: Narrow-band imaging in diagnosis of endometrial cancer and hyperplasia: a new option? $J$ Minim Invasive Gynecol 17: 2010, 620-25.

\section{How to cite this article:}

Stuti Tyagi et al (2017) 'Clinical Application Of Spectra A Mode In Hysteroscopy Guided Endometrial Biopsy', International Journal of Current Advanced Research, 06(05), pp. 3822-3825.

DOI: http://dx.doi.org/10.24327/ijcar.2017.3825.0375 